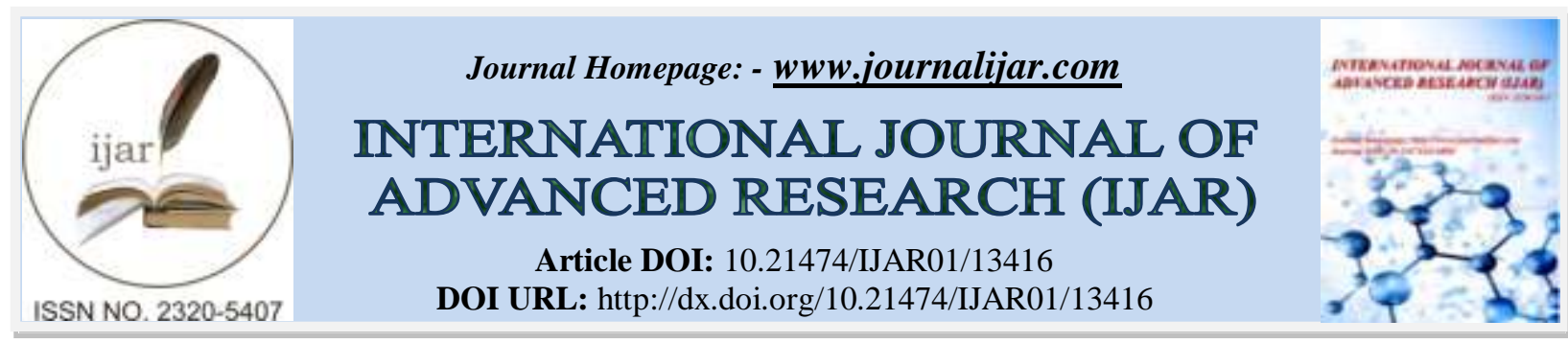

RESEARCH ARTICLE

\title{
COMPARATIVE STUDIES OF THE SUSCEPTIBILITY OF COPPER AND ALUMINUM TO PROCESSING IN WIRE DRAWING PROCESS
}

\author{
B. Smyrak ${ }^{1}$, B. Leszczyńska Madej ${ }^{1}$, P. Jalowy ${ }^{2}$, M. Nowak ${ }^{3}$ and P. Kozak ${ }^{3}$ \\ 1. Associate Profesor, AGH-University of Science and Technology, Krakow, Poland. \\ 2. PhD Student, AGH Universisty of Science and Technology, Krakow, Poland. \\ 3. PhD, Aptiv, Krakow, Poland.
}

\section{Manuscript Info}

Manuscript History

Received: 19 July 2021

Final Accepted: 23 August 2021

Published: September 2021

Key words:-

Copper, Aluminium Cables, Wires, Wire Drawing, Metal Forming

\begin{abstract}
Modern technological solutions in electrical applications require, above all, high energy efficiency. This means that in such applications, materials with the highest possible electrical conductivity should be used for conductive elements. Of all metals, copper is the natural choice. Copper cables or wires used in electrical networks and installations provide better electrical and thermal conductivity and guarantee reliability - which translates into the quality of electricity. And bad quality of energy means tangible financial losses. On the other hand, apart from physical properties, an important factor is the price of cables and wires, which is partially dependent on the price of copper on the stock exchange. The last 20 years have seen a high increase in copper prices on the markets and at the same time the price is unstable. Therefore, cheaper substitutes for copper are being sought. The natural choice is aluminum, which is currently widely used in overhead power lines. At the same time, in the case of long cables, copper products still dominate. The paper presents a synthetic comparative analysis of technological processing problems in industrial drawing processes of aluminum and copper wires used in electrical applications.. In particular, comparative analysis applied the susceptibility into formability in the wire drawing process and susceptibility to recrystallization annealing of copper and aluminum wires. The drawing process and the annealing process are simple processes for the production of wires used for electrical purposes.
\end{abstract}

Copy Right, IJAR, 2021,. All rights reserved.

\section{Introduction:-}

Copper is the material traditionally used in electrical applications because it is the second best conductor of both electricity and heat. Table 1. presents basic properties of aluminium and copper. Note that while the resistivity of copper is lower than that of aluminium, the mass density of copper is much higher than the massdensity of aluminium. The expansion coefficient of copper is lower than that of aluminium, but the thermal conductivity is higher in copper than in aluminium. Also, note that the tensile strength of copper is superior.

Corresponding Author:- B. Smyrak

Address:- Associate Profesor, AGH-University of Science and Technology, Krakow, Poland. 
Table 1:- Comparison of properties of copper and aluminium.

\begin{tabular}{|c|c|c|c|}
\hline Property & Unit & Copper & Aluminium \\
\hline Density & $\mathrm{kg} / \mathrm{dm}^{3}$ & 8900 & 2700 \\
\hline Tensile strength (hardened state) & $\mathrm{MPa}$ & 350 & 180 \\
\hline Tensile strength (annealed state) & $\mathrm{MPa}$ & 220 & 80 \\
\hline Ultimate elongation (hardened state) & $\%$ & 1 & 1 \\
\hline Ultimate elongation (annealed state) & $\%$ & 35 & 35 \\
\hline Modulus of elasticity & $\mathrm{GPa}$ & 120 & 70 \\
\hline Melting point & ${ }^{\circ} \mathrm{C}$ & 1083 & 660 \\
\hline Thermal expansion coefficient & $10^{-6} /{ }^{0} \mathrm{C}$ & 16.6 & 23.8 \\
\hline Temperature resistance coefficient $+20^{\circ} \mathrm{C}$ & $1 /{ }^{0} \mathrm{C}$ & 0.0039 & 0.0041 \\
\hline Electrical conductivity at $20^{\circ} \mathrm{C}$ & $\%$ IACS & 100 & 61 \\
\hline Resistivity at $20^{\circ} \mathrm{C}$ & $\mathrm{n} \square \mathrm{m}$ & 17.24 & 28.26 \\
\hline
\end{tabular}

A properly designed conductor is the basic element ensuring safe and failure-free operation of overhead power lines. The conductor's material and structure should guarantee that the power transfer is not only a failure-free and safe, but also cost-effective. Therefore, the conductive materials intended for conductors of overhead power lines should meet the following requirements:

1. high electrical conductivity,

2. low per unit mass,

3. high strength properties,

4. high heat, rheological, and fatigue resistances.

The high electrical conductivity requirements results from the basic role played by the conductor, however other requirements depend on its operating conditions. Thus, important parameters include, apart from high static and fatigue resistance, adequate heat resistance allowing for high current-carrying capacity of the line, creep resistance and corrosion resistance depending on place of installation. While analysing all metals of the periodic system, it is easy to notice that the best conducting materials are metals of group 11 (copper, silver, gold). Among them, only copper meets all the aforementioned requirements.

For the mass-production of aluminum harnesses, it is necessary to enable the crimping connection (a general method in harness manufacturing) for connecting the aluminum wire to the terminal. It is known that these properties vary depending on the crimping condition (crimping strength). That is, crimping conditions for harness manufacturing must be in the range where both the required electrical connection and wire retention force can be obtained. Table 4 shows the copper and aluminum properties and effects on crimping connection of aluminum wires. Among these properties, the surface oxide film may have the largest effect because the aluminum surface is covered with a robust insulating oxide film. Therefore, we assumed that breaking this insulating oxide film would be the greatest challenge in the crimping process to ensure effective electrical connection. Figure 6 shows the newly developed crimping terminal for the aluminum wire. The connection performance has been ensured simply by modifying the serration [1].

Table 2:- Copper and aluminium properties and effects on crimping.

\begin{tabular}{|c|c|c|c|}
\hline Properties & Copper & Aluminium & effect on crimping \\
\hline surface oxide film & $\mathrm{Cu}_{2} \mathrm{O}$ & $\mathrm{Al}_{2} \mathrm{O}_{3}$ & insulating oxide film \\
\hline conductivity of oxides, s/cm & 10 & $10^{-7}$ & \multirow[t]{2}{*}{ increase contact resistance } \\
\hline conductivity of base material, \%iacs & 100 & 60 & \\
\hline coeffiecient of thermal expansion $\times 10-6,1 /{ }^{\circ} \mathrm{C}$ & 17.1 & 23.6 & $\begin{array}{l}\text { large variation in contact load } \\
\text { relative to variation in temperature } \\
\Rightarrow \text { decrease in contact load, } \\
\text { particularly on low temperature side }\end{array}$ \\
\hline
\end{tabular}

In recent decades, automotive cables based on aluminum and aluminum alloys have been very popular among car manufacturers. In particular, this material is used for wires in automotive wiring harnesses. The biggest challenge in the manufacture of aluminum cables for the automotive industry is to achieve a compromise between satisfactory electrical conductivity of the cable and good mechanical parameters. Pure aluminum or aluminium alloys with small 
additions of elements (most often 1000 series) show the best electrical conductivity. A slight content of other elements in aluminum alloys has a negligible impact on the material resistance, which results in higher electrical conductivity of the finished product [2]. Until now, the smallest cables used in pure aluminum that are suitable for mass production are cables with a cross section of $0.75 \mathrm{~mm} 2$ [3]. Such a cable is constructed of seven independent wires with a diameter of $0.38 \mathrm{~mm}$ each (Fig. 2). The ISO 6722-2 standard itself, which characterizes aluminum cables for the automotive industry, does not provide cables with smaller cross-sections [3]. While veins with larger diameters for such materials are produced without any problem, so pulling tests into smaller diameters can lead to wire breakage during the drawing process. An important role here is the low tensile strength of pure aluminum, and the fact that aluminum is rapidly covered with an oxide layer, which peeling on dies can disrupt the correct plastic working process in industrial conditions, where the drawing speed reaches up to $30 \mathrm{~m} / \mathrm{p}$. Other technological problems encountered in cables made of 1000-series aluminum alloys are low mechanical properties and susceptibility to creep even at room temperature. Requirements for products in the automotive industry, due to high care for safety as well as reliability, are restrictive, therefore it happens that these materials do not meet the requirements set for them. In these cases, precipitation curing as well as special alloys are a great alternative. A big challenge for aluminum cables used in the automotive industry is to ensure adequate rheological resistance. Aluminum alloys, in particular alloys with the highest content of this metal, tend to creep at low temperature. Particularly problematic in this respect seems to be the connection of the electrical connectors on the cable ends (terminals), which is usually carried out by mechanical crimping. Stresses caused by such attachment of the terminal to the cable may be relaxed -during operation, resulting in the interruption of the connection between the cable and the lack of electricity flow [4-5].

\section{The object}

The feedstock for the drawing process is most often wire rod produced in a continuous casting and rolling line. On the other hand, commonly used drawing machines are single-strand or multi-strand multi-strings operating by immersion or in the mist of the lubricating medium. Traditionally, these are machines with a blocked drive, although nowadays non-skid drawing machines with an individual drive are used more and more often, on which individual unit elongation factors can be freely selected. The drawing process - depending on the diameter of the final product is carried out using a thick-line, medium-line and micro-line.

In the case of the drawing process of wires with diameters below $0.1 \mathrm{~mm}$, the importance of problems related to the quality of the material (amount of impurities, type of structure, surface quality) ultimately determines the possibility of using a given material for micro-wires. In turn, with regard to the factors related to the drawing process, the ductility limitations may be the result of too small deformations in individual drawing stages, bad die geometry and improperly selected lubricants and drawing emulsions. For the production of aluminum wires, mainly aluminum of EN AW-1370 grade is used. Chemical quality of the above-mentioned material guarantees the production of wires with a diameter of about $200-150 \mu \mathrm{m}$ in industrial conditions. In turn, in the case of copper, the ductility threshold is an order of magnitude higher and is below $100 \mu \mathrm{m}$.

The aim of the article is a comparative study of the susceptibility of processing into wires for electrical applications of both materials. In particular, it is aboutdetermination of deformability in the process of drawing aluminum and copper wires.

\section{Research programme and material}

Detailed research program with test parametres is shown in the table 1

Table 3:- Wire rod test parameters.

\begin{tabular}{|c|c|c|c|}
\hline Material/parameters & $\begin{array}{c}\text { Mechanical } \\
\text { properties } \\
\text { (UTS, Proof Stress, } \\
\text { Elongation) }\end{array}$ & $\begin{array}{c}\text { Electrcial } \\
\text { properties } \\
\text { (resistivity) }\end{array}$ & $\begin{array}{c}\text { Microstruture } \\
\text { (images from scanning } \\
\text { electron microscopy, optical } \\
\text { microscopy) }\end{array}$ \\
\hline Copper and aluminium wirerod & $\mathrm{x}$ & $\mathrm{x}$ & $\mathrm{x}$ \\
\hline $\begin{array}{c}\text { Copper and aluminiumwires after drawing } \\
\text { process }\end{array}$ & $\mathrm{x}$ & $\mathrm{x}$ & $\mathrm{x}$ \\
\hline
\end{tabular}




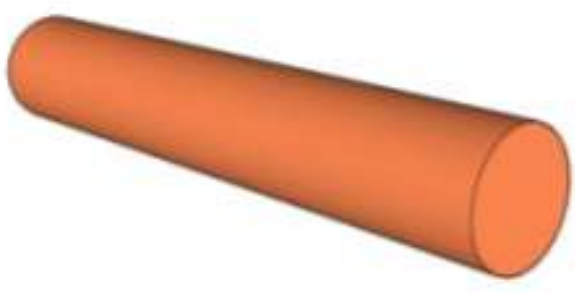

Fig.1:- Scheme of wire rod.

Aluminium wire rod $(9.5 \mathrm{~mm})$ diameter was produced on the ContinuuseProperzi ${ }^{\circledR}$ continuous casting and rolling mill line and $8 \mathrm{~mm}$ diameter $\mathrm{Cu}$ wire rod was produced using the Contirod $\AA$ line. The chemical composition of $\mathrm{Al}$ and $\mathrm{Cu}$ wire rods is presented in Tables 2 and 3.

Table 4:- Chemical composition of aluminium wire rod (grade EN AW - 1370).

\begin{tabular}{|c|c|c|c|c|c|c|c|c|c|c|}
\hline \multicolumn{10}{|c|}{ Elementscontent, wt.\% } \\
\hline $\mathrm{Al}$ & $\mathrm{Si}$ & $\mathrm{Fe}$ & $\mathrm{Cu}$ & $\mathrm{Mn}$ & $\mathrm{Mg}$ & $\mathrm{Ni}$ & $\mathrm{Zn}$ & $\mathrm{Ti}$ & $\mathrm{Ga}$ & $\mathrm{V}$ \\
\hline 97.78 & 0.032 & 0.09 & 0.036 & 0.0018 & 0.0011 & 0.0002 & 0.027 & 0.0002 & 0.0087 & 0.0033 \\
\hline
\end{tabular}

Table 5:- Chemical composition of copper wire rod (grade ETP).

\begin{tabular}{|c|c|c|c|c|c|c|c|c|c|c|c|c|c|c|c|c|c|c|c|}
\hline $\begin{array}{c}\text { Mater } \\
\text { ial }\end{array}$ & $\begin{array}{c}\mathrm{S} \\
\mathrm{b}\end{array}$ & $\mathrm{As}$ & $\mathrm{Bi}$ & $\mathrm{Cr}$ & $\begin{array}{c}\mathrm{S} \\
\mathrm{n}\end{array}$ & $\mathrm{Zn}$ & $\mathrm{P}$ & $\mathrm{Cd}$ & $\mathrm{Co}$ & $\begin{array}{c}\mathrm{S} \\
\mathrm{i}\end{array}$ & $\begin{array}{c}\mathrm{M} \\
\mathrm{n}\end{array}$ & $\mathrm{Ni}$ & $\mathrm{Pb}$ & $\begin{array}{c}\mathrm{S} \\
\mathrm{e}\end{array}$ & $\mathrm{S}$ & $\begin{array}{c}\mathrm{T} \\
\mathrm{e}\end{array}$ & $\mathrm{Fe}$ & $\mathrm{Ag}$ & $\begin{array}{c}\text { Oxyg } \\
\mathrm{en}\end{array}$ \\
\hline $\mathrm{Cu}-$ & 0. & 0.4 & 0.7 & 0.0 & 0. & 1.3 & $<$ & 0.0 & 0.0 & $<$ & 0. & 1.6 & 1.4 & 0. & 5. & 0. & 1.0 & 16. & 165 \\
$\mathrm{ETP}$ & 2 & 6 & 4 & 5 & 6 & 7 & 2 & 5 & 5 & 2 & 2 & 6 & 7 & 2 & 6 & 2 & 7 & 5 & \\
\hline
\end{tabular}

\section{Results:-}

First, the raw material for the wire drawing process, i.e. copper and aluminum wire rod, was analyzed. The drawing shows the tensile characteristics of both materials. We note that in the case of Cu-ETP wire rod, both the strength (UTS, and Proof Stress) and plastic properties (elongation) are almost twice as high as compared to aluminum wire rod. A similar observation applies to plastic properties, in this case the difference is several percent.
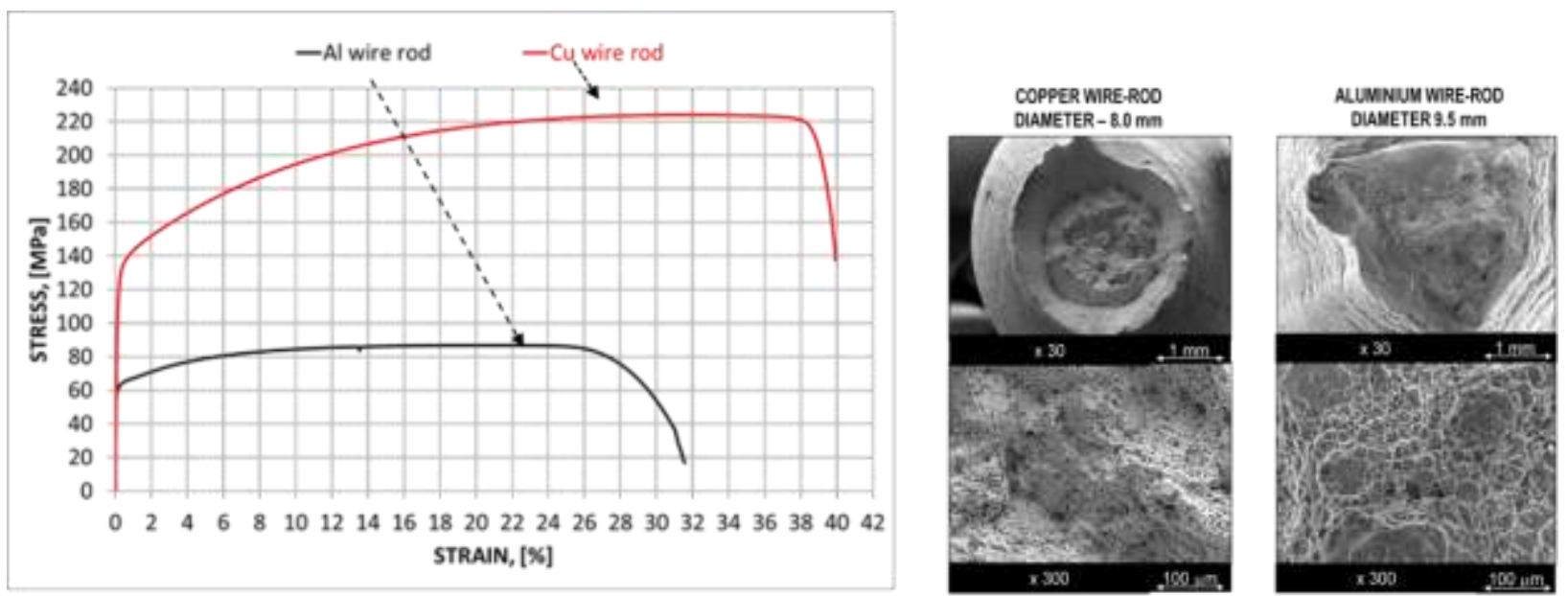

Fig.1:- Tensile -strength characteristics of aluminium wire rod and copper wirerod and SEM imagaes of fracture after tensile test.

The figure shows the microstructure of the longitudinal section of the copper and aluminum wire rod. The main difference is related to the grain size and the homogeneity of the structure. The grain size of an aluminum wire rod is approx. 30 micrometers, while that of an aluminum wire rod is approx. a1-2 $\mathrm{mm}$. In addition, the microstructure of copper wire rod is homogeneous throughout the volume, while in the case of aluminum wire rod, a non-uniform 
strand structure is observed. Based on the observation of the microstructure, it can be concluded that the $\mathrm{Cu}$ wire rod shows a fully recrystallized microstructure, while the aluminum rod shows the microstructure after hot forming, in which the recovery processes took place.

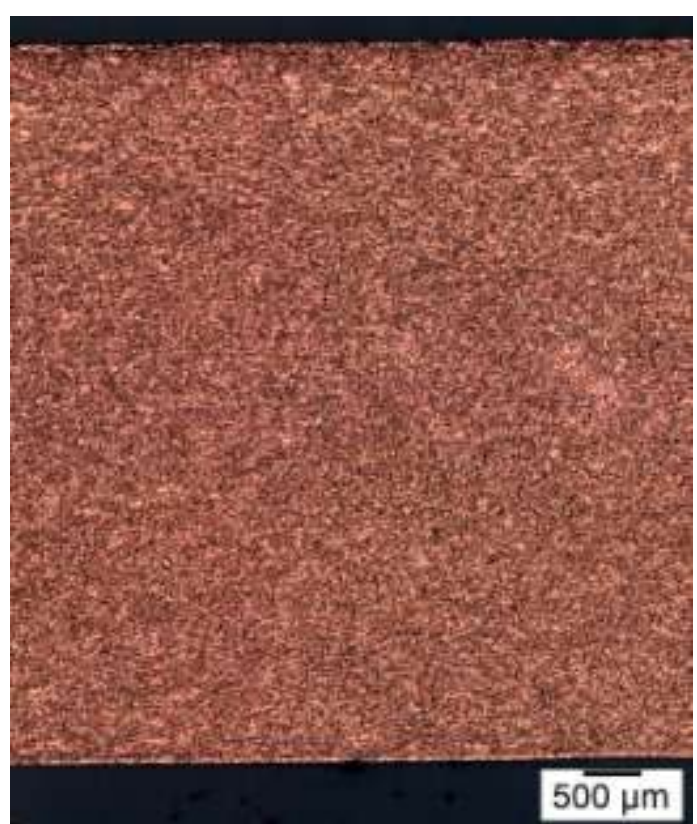

Fig.2:- Cu-ETP wire rod -longitudinual section.

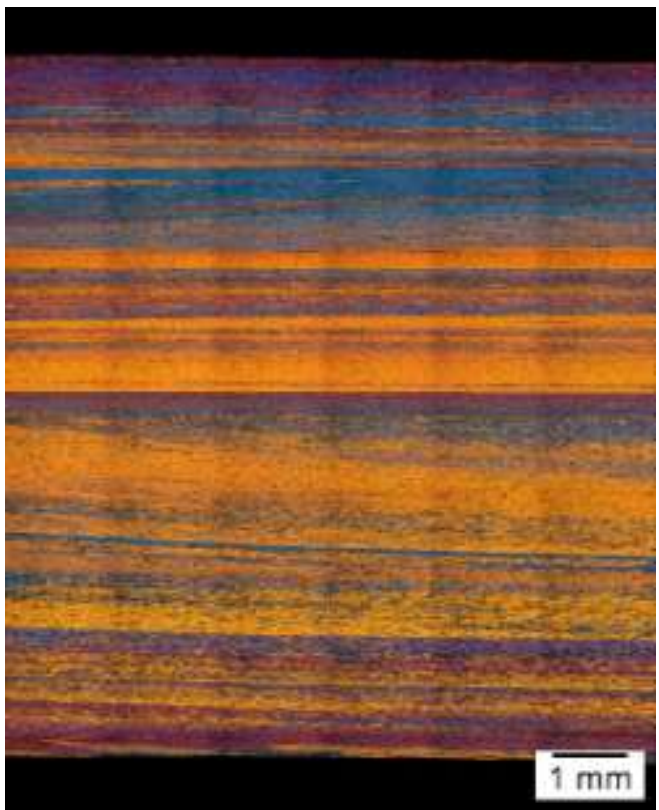

Fig.3:- EN-AW 1370 wire rod -longitudinual section.

The consequence of differentiation of the microstructure of $\mathrm{Al}$ and $\mathrm{Cu}$ wire rod is the differentiation of susceptibility to the drawing process. In particular, it concerns the deformability and the dynamics of strengthening of the wires during the drawing process. Fig. 4 shows the results of the influence of the deformation size on the conventional yield strength of copper (white points) and aluminum (black points) wires.
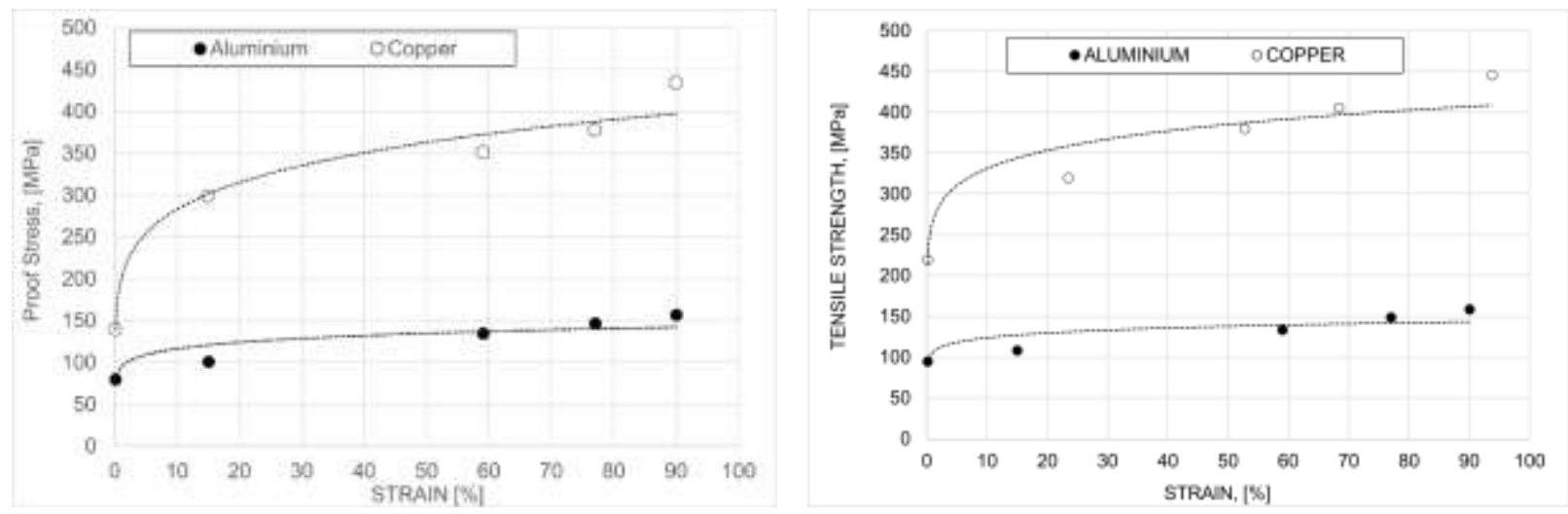

Fig. 4:- Impact of strain hardening on the proof stress (left) and UTS (right) of copper and aluminium wires after drawing process.

The analysis of the above diagram showed that the increase in the yield stress for the same deformation value is greater in the case of $\mathrm{Cu}$-ETP wires and amounts to approx. $150 \%$ in relation to the initial value. For comparison, for wire rod Al. the increase of Proof Stress is about $60 \%$.

The identical analysis for the UTS shows a similar relationship between the amount of deformation and the tensile strength of the $\mathrm{Al}$ and $\mathrm{Cu}$ wires. The increase in UTS due to deformation is lower than in the case of the Proof Stress value. This observation applied both materials (copper and aluminium) - see Fig. 5. 


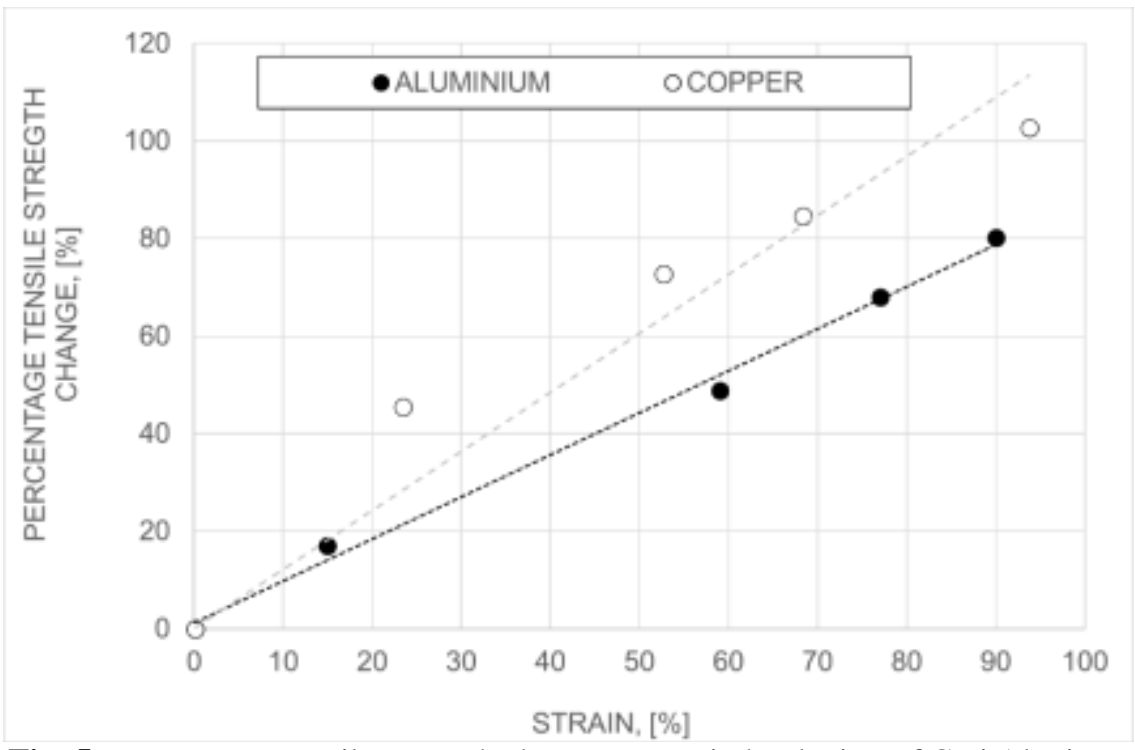

Fig. 5:- Percentage tensile strength change vs. strain hardening of $\mathrm{Cu}$ i $\mathrm{Al}$ wires.

In the case of impact of strain hardening on the $\mathrm{Cu}$ i $\mathrm{Al}$ wires plasticity it was stated that value elongation drop more for aluminium wires (Fig. 6).

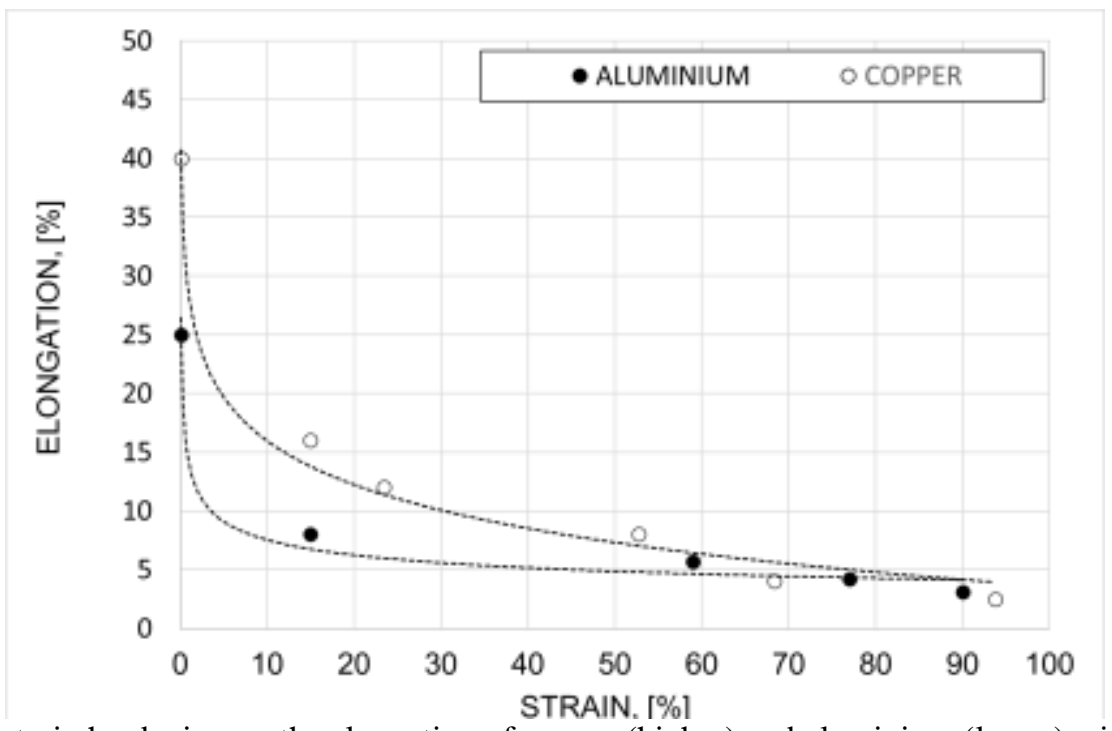

Fig.6:- Impact of strain hardening on the elongation of copper (higher) and aluminium (lower) wires after drawing process.

\section{Conclusion:-}

On the basis of the conducted research, it was found that copper is characterized by better deformability in the drawing process than aluminum. The above fact is due to the following reasons:

1. Cu-ETP wire rod is characterized by twice higher strength properties and at the same time greater plasticity compared to Al wire rod.

2. Cu-ETP wire rod is characterized by a homogeneous, fine-grained structure - the grains are of the same size with a typical shape after the recrystallization process. Al wie rod has a heterogeneous structure - the grains are elongated - a typical structure after the hot shaping process (after the recovery process).

3. The average grain size of $\mathrm{Cu}$-ETP wire rod is approx. 30 micrometers, in the case of $\mathrm{Al}$ wire rod. - average grain size - 1-2 mm. 
4. An increase in the amount of deformation in the drawing process leads to an increase in UTS and Proof Stress as well as a decrease in plasticity. In the case of copper wire rod, the increase in strength properties as a result of the amount of deformation is greater than in the case of Al wire rod. In turn, the decrease in plasticity due to deformation in the case of copper is less than in the case of aluminum.

\section{Literature:-}

[1]. Comparative study of the application of steels and aluminium in lightweight product tion of automotive parts; Miklos Tisza, ImreCzinege,

[2] The influence of trace elements on the microstructures and properties of the aluminum conductors; XuexiaXa, Yanting Feng, Peng Yang, BaoruiZhana, Yong Wang, Qing Wang ,Xiaoliang Fan, Haimin Ding,Results in Physics, Volume 11, December 2018, Pages 1058-1063

[3] Standard ISO 6722-2:2013, Road vehicles - $60 \mathrm{~V}$ and $600 \mathrm{~V}$ single-core cables - Part 2: Dimensions, test methods and requirements for aluminium conductor cables

[4] Aluminium cables in automotive applications, Prestudy Of Aluminium Cable Uses In ScaniaProducts Failure Analysis And Evaluation; Man Yu, 2016

[5] R.Davis, Aluminium Handbook, 2010. 